\title{
Chapter 3 \\ Life Cycle Management as a Way \\ to Operationalize Sustainability Within Organizations
}

\author{
Sarra Harbi, Manuele Margni, Yves Loerincik, and Jon Dettling
}

\begin{abstract}
This chapter proposes a value creation framework to operationalize sustainability within organizations through an improved link between life cycle management tools and business drivers for value creation. Internal and external stakeholders' need to be first identified and accounted for, and value creation must be clearly identified in order to be acknowledged and communicated. The question "what do we want to achieve?" needs to be answered before thinking how to best achieve the identified business value. We propose to apply "reverse-engineering" to define the value creation path and identify the departments and collaborators to be involved at different level of the organization. LCM offers an essential and flexible integrated management framework of concepts, techniques and procedures to think how to best operationalize sustainable actions to achieve the identified business value. The sustainability action involves a team that should include, at least a sponsor or a pilot from the department that is expecting final value creation (Human Resources - HR for employee engagement, marketing for product positioning, etc.) and a representative from each department involved in the value creation path. Each of them will need an LCM tool adapted to their need and specific objectives. Last but not least, one needs measurable indicators on global goals that are to be monitored by the overall project sponsor, through KPI (key performance indicators) and follow-up.
\end{abstract}

\footnotetext{
S. Harbi • Y. Loerincik

Quantis-International, EPFL Innovation Park, Bât D, CH-1015 Lausanne, Switzerland

M. Margni (四)

Quantis-International, EPFL Innovation Park, Bât D, CH-1015 Lausanne, Switzerland

CIRAIG, Polytechnique Montréal, C.P. 6079, Succ. Centre-Ville,

Montréal, QC H3C 3A7, Canada

e-mail: manuele.margni@polymtl.ca

J. Dettling

Quantis-International, 295 Hanover Street, Suite 4A, Boston, MA 02113, USA
}

(C) The Author(s) 2015

G. Sonnemann, M. Margni (eds.), Life Cycle Management,

LCA Compendium - The Complete World of Life Cycle Assessment,

DOI 10.1007/978-94-017-7221-1_3 
Keywords Life cycle assessment $\bullet$ Life cycle management $\bullet$ Sustainability $\bullet$ Value creation

\section{Introduction}

The role sustainability plays differs from one organization to another. This is also true across different functions within the same company. Indeed, an organization is not homogeneous, and the needs of departments such as operations, marketing, product development, sales and other stakeholders within the company are often very different. They are also very different in how they are impacted by the risks and opportunities posed by the sustainability topic. A one-fit-for-all solution to make sustainability operational within an organization is therefore not feasible, but rather the right approach needs to be tailored to the unique context, resources and constraints of the company or department in question.

Many companies have started their journey towards sustainability in response to stakeholder or customer requests, or sometimes through a strong personal commitment of key individuals. However, today's corporations are inherently profit-driven by the necessity of competition and so, to be integrated into the company and become part of the company's DNA and strategy, sustainability needs to create value for the corporation itself (Bonini and Schwartz 2014). If not connected to the business it can easily be disregarded in challenging economic conditions. In addition, today's corporations conduct their core business with great efficiency and alignment of sustainability with these core operations ensures a rapid and effective trajectory for achieving outcomes in comparison to treating sustainability work as a form of philanthropy.

Systematic integration of sustainability into strategic initiatives is key to achievement of meaningful sustainability related goals, since the long-term changes required are likely to be drastic departures from today's status quo and the path to achieving them is often as-yet unclear and quickly evolving. A strategic focus on sustainability allows appropriate actions to be taken at the right moment, as the context of the sustainability discussion plays out over the long term. Life cycle thinking is a key to achieving this strategic alignment by allowing companies to understand their position within the broad context of sustainability. Today's leaders in the sustainability space are continually finding creative ways to adapt life cycle thinking to the whole organization as well as its products and services, thus leading to a better understanding of consumer preferences, stakeholder pressure, existing regulation and future trends.

Life cycle management (LCM) is "a flexible integrated management framework of concepts, techniques and procedures incorporating environmental, economic, and social aspects of products, processes and organizations" (UNEP 2006, UNEP/ SETAC 2009) to achieve the integration of sustainable development into the company, along the whole value chain (O'Rourke 2014). 


\section{Value Creation and Life Cycle Management}

Value creation and differentiation are keys for companies. Today, the strong correlation between good financial performance and sustainability is widely accepted and recognized (DB Climate Change Advisors 2012). It is clear that businesses strategy that includes sustainability programs contribute to strong corporate performances.

A growing number of examples show that sustainability initiatives are a great catalyst to creating profit as well as new business opportunities. How to link sustainability to business value is, however, still poorly understood by a large majority of companies (Accenture and United Nations Global Compact 2013).

Companies seeking to pursue the sustainability path need to ensure that they do so while creating value for the company itself and along its value chain. Sustainability for the sake of sustainability is well-meaning, but likely to be ineffective. Without expressing the value creation of sustainability, companies will remain in "pilot projects" or small-scale sustainability projects, only able to engage and motivate those internal sponsors and team members that "buy-in" to the sustainability mission as a matter of personal conviction and unable to find the right strategies to leverage to core power of the business. Identifying the business value created by sustainability and the way to get there is thus essential. The value has to be perceived along the whole value chain, i.e. managers and collaborators at different levels of the company as well as external stakeholders whose expectations and potential influence must be identified and accounted for. Finally, this value creation must be measurable and measured in order to be acknowledged and communicated.

A key step each company should consider before embarking on the path of sustainability is answering the question "What is the value this strategy will generate for our organization?" Recognizing that each company's path to capturing value from sustainability will be unique, Bonini and colleagues $(2011,2014)$ proposed a framework that can serve as a universal starting point to understand the relationship between sustainable initiatives and value creation. It captures value in three key areas:

- Risk management linked to sustainability - encompass risks due to operational disruptions such as, for example, resource scarcity, extreme events from climate change; risk due to reduced reputation from relationship issues with stakeholders along the value chain; and regulatory risk from current restrictions and regulations to come.

- Return on capital - by onsite operational efficiency through improved resource management, e.g. energy efficiency, water reuse and byproduct valorization; by developing sustainable value chains expanding improved resource management efficiency through the supply chain or downstream extending producer responsibility; by increasing employee motivation through internal involvement and identification to company and its values; and by green sales and marketing seeking increased revenue from sustainability attributes. 
- Growth - by innovation and the development of new sustainability driven product/service development; by developing strategies opening the door on new markets; and by regularly revisiting the composition of business portfolios to determine trends and potential risks and improve appeal for investors, as well as by competing better with existing products/services, as customers and consumers place increasing emphasis on sustainability in their purchasing decisions.

It is very important to remember that sustainability in itself is not necessarily generating value for an organization, unless it becomes aligned with the company's core business strategy.

\subsection{Defining the Strategy of Sustainable Value Creation}

The first step when defining a sustainable strategy is to define the expected outcomes. The first and most important question to be answered is about the expected business value from implementation of the sustainability action plan. In order to answer this question, one should:

(a) Align with the company strategy: Is the priority of the company to grow and to develop? To increase its margin? How is this going to be achieved? Sustainability should be used to support the company's strategic priorities.

(b) Assess stakeholders expectations: What stakeholders have an interest in sustainability and are to be involved? What is their influence on the company and its value-chain? On what type of value can they act? For example, clients will influence sales, key opinion leaders will influence brand reputation and suppliers of strategic materials can influence the level of risk.

(c) Perform a risk assessment: A sustainability strategy can be key to support the risk management plan of a company.

A meaningful strategy to unlock sustainability within an organization remains the key to link each initiative to one of the key areas of value creation. We can think at the life cycle management toolbox being at the opposite end of the value creation path within a company. Often an appropriate LCM tool (or a combination of them) is first identified, and then implemented by a business unit that is expected to generate tangible or intangible business benefits. Proceeding in such a sequence, however, is risky. Organizations might realize that generated business benefits are not aligned with company's value drivers like two ends of a tunnel being drilled from both sides that fails to meet in the middle due to poor planning.

There are potentially many good reasons to launch an ecodesign project:

- Starting from consumers expectations and perspective, developing a new packaging that is differentiated by its lower impact on the environment. But the first questions to tackle are: What does sustainability mean for the consumers? How do they perceive it? How will they react to a new packaging? 
- Generating new ideas thanks to the motivation of the team to work on sustainability. It is however important to understand the expectations of the team: How do they perceive sustainability? What would they like to learn during the process? How is their work valued?

- Limiting risks by choosing appropriate materials. Which material price will be less influenced by the future price of energy? Which materials have an availability that is ensured for the coming 20 years?

The following example shows that one first needs to define the value to be created with sustainability, before launching a sustainability action.

\subsubsection{The Liberté Case Study}

Liberté, a dairy company based in Québec implemented in 2008 an ecodesign strategy, working on various products, but in particular on a drinkable organic yogurtbased beverage that was to be sold in a cardboard packaging. Liberté discovered through a life cycle assessment that this new packaging had a significantly lower impact on the environment than the plastic bottle traditionally found on the market.

The product, launched in 2008, was positioned as an ecodesigned product (organic milk and packaging optimized with a life cycle assessment). Unfortunately, the launch of the product was not the commercial success that the company's management had anticipated. Several reasons can be identified:

- In some cases, retailers and consumers were negatively surprised by the packaging design that was different than the industry norms for such a product. This is even though the product was sold among the organic products, where buyers are relatively well informed on sustainability issues.

- The Producteurs de lait du Québec (Milk Producers of Liberté) were subsidizing single portion dairy products with an additional premium for drinkable products packaged in a resealable plastic bottles favouring "on-the-go" consumption.

- Consumers (especially young children) were not used to the new packaging and had some difficulty opening them.

The learnings for Liberté were the following. They were able to determine hotspots linked to the environmental impacts of their product and were capable to mobilize the necessary resources and collaborate with suppliers to address them. However, although meeting the objective of a more sustainable packaging, the company failed to understand consumer's perceptions and needs. A better link between $R \& D$ and marketing needs to be established to test market perceptions in respect to these new products. This is especially true where such products counteract existing market trends, and in such cases, it is necessary to understand the likely consumer acceptance and whether consumer education or other actions need to be focussed on. 


\subsection{Sustainability Value Creation Framework}

In order to minimize such implementation "failures", the authors propose a sustainability value creation framework that builds on life cycle management, but ensures at the same time connectivity between the selected LCM tools and the value drivers of the company (Fig. 3.1).

The framework describes the links between life cycle management tools and value creation through different steps: toolbox, business implementation, business benefits, value drivers and business value. One proceeds from left to right by asking the question "for what purpose", or "what do we want to achieve". From right to left, one can ask the question "how?" The value creation framework has to be defined for each company, and in many cases, the path toward value creation might be longer and more sophisticated than what is presented in Fig. 3.1.

Although one can easily start from anywhere within the framework, addressing the two questions and clarifying the chain is the starting point to ensure the linkage between sustainability actions and business value creation for the company. In Sect. 3, several of these paths to sustainable value creation are illustrated and discussed.

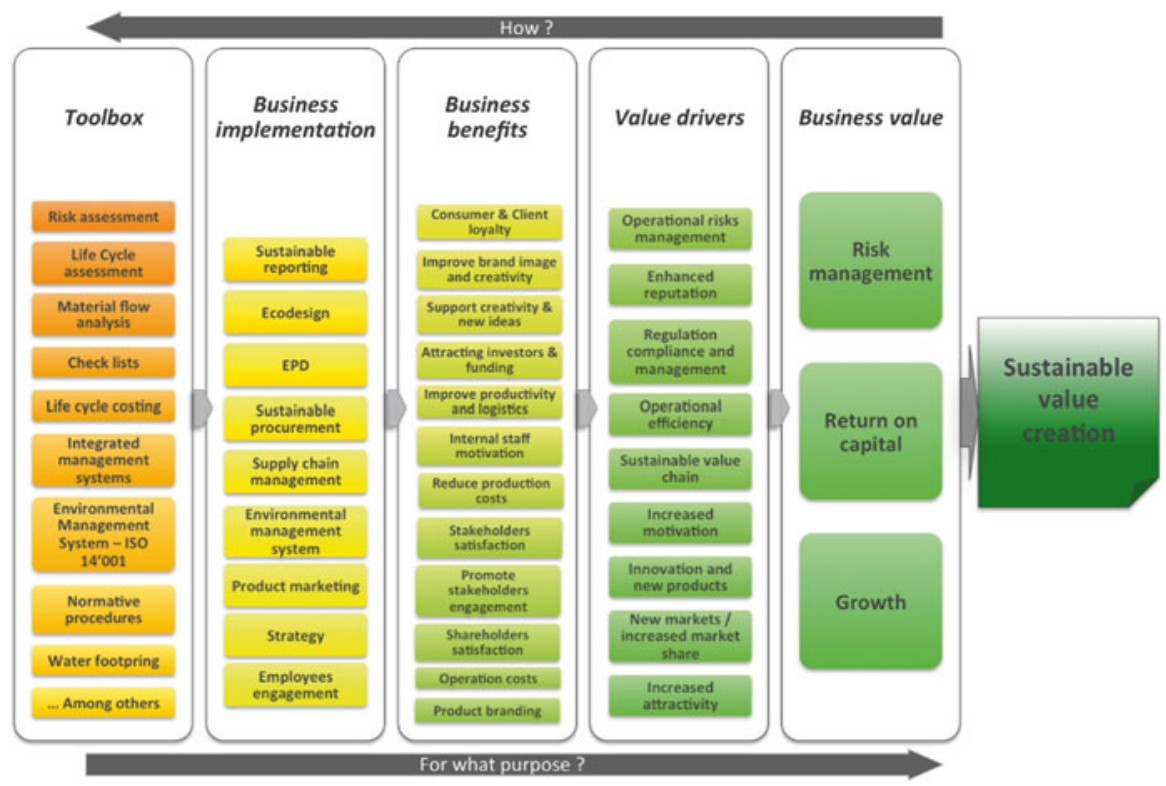

Fig. 3.1 Sustainability value creation framework linking life cycle management tools with business value creation of an organization 


\section{Paths to Operationalize Sustainability Through Life Cycle Management in a Company: Illustrated Applications}

\subsection{Sustainability as a Motivation Generator}

\subsubsection{What Leading Companies Are Saying About Sustainability Value Creation Through Employees Engagement?}

Employees are increasingly considered as a key stakeholder group in driving companies to take action on sustainability issues (Accenture and United Nations Global Compact 2013). For example. Beiersdorf's Sustainability report clearly illustrates this pathway of value creation for companies: Nowadays, employees express a strong interest in sustainability issues. They want to work for a company that shares their values and actively engages them in its sustainability commitment. This is becoming an ever more important requirement to attract, retain and motivate employees. We firmly believe that we can only increase our sustainability commitment with the support of our employees. In order for our sustainability strategy to be effective and achieve its targets, our employees need to understand what sustainability means to them in private and in business terms and how they can actively contribute. This in turn leads to increased motivation and enhanced performance, which benefits our business. (Beiersdorf 2013).

Starbucks is also a leading example illustrating the integration of employees, called "partners" by Starbucks, as key stakeholders for the company and its value: The management of Starbucks considers that one of the major reasons for Starbucks success is the "partners" and the relationship they form each day with the customers, and not the coffee itself. Starbucks thus invests a lot in its employees through equal treatment, a strong internal communication and feedbacks politic as well as social measures. This creates an interactive structure with "partners" in the center that makes the employees commit and identify themselves with the company. Starbucks sells the concept of the brand to their employees first, making them part of the story and ensuring their personal investment in the company's development, as they believe in the company and contribute to its success out of self-interest. (Starbucks, Global responsibility report 2013). "We built the Starbucks brand first with our people, not with consumers. Because we believed the best way to meet and exceed the expectations of our customers was to hire and train great people, we invested in employees." (Starbucks 2013). 


\title{
3.2 Sustainable Supply Chain to Reduce Risks
}

\subsubsection{What Leading Companies Are Saying About Sustainability Value Creation Through Risk Avoidance?}

\author{
Nestlé Example
}

\begin{abstract}
Better management of risks that arise from sustainability issues begins with detecting key risks of operational disruptions from climate change, resource scarcity, or community issues (such as boycotts or delays in getting permits for manufacturing) (Carbon Disclosure Project 2013). Faced with potential supply constraints, Nestlé, for example, launched a plan in 2009 that coordinates activities to promote sustainable cocoa: producing 12 million stronger and more productive plants over the next ten years, teaching local farmers efficient and sustainable methods, purchasing beans from farms that use sustainable practices, and working with organizations to help tackle issues like child labor and poor access to health care and education. (Bonini and Schwartz 2014)
\end{abstract}

\section{Michelin Example}

Around $40 \%$ of a truck tire by weight is natural rubber and tire manufacturing uses $70 \%$ of the world's output of natural rubber, whose exceptional physical properties make it irreplaceable for truck, aircraft, agricultural and earthmover tires. (Michelin 2010)

Demand is constantly rising and therefore developing and maintaining rubber tree farms is a major priority for Michelin, which uses nearly $10 \%$ of the world's natural rubber output.

Michelin recognized the risk represented by the raw materials, energy and nonrenewable resources required for its products and production, as these resources, like oil or natural rubber, are becoming scarcer and more expensive. "In 2010, raw material costs represented $27 \%$ of Michelin's net sales. Optimizing their use is essential if these resources are to be conserved over the long term and if tires are to remain affordably priced." (Michelin 2010).

Michelin is therefore working on engineering lighter tires that require less raw material and improve energy efficiency by optimizing the rolling resistance. Besides this strategy, the tire maker is also investigating alternative solutions to limit the pressure on primary resource supply through regrooving and retreading. Michelin is applying the life cycle assessment approach to ensure that such alternatives will not create value for Michelin while shifting environmental burdens elsewhere. 


\subsection{Sustainability to Increase Brand Perception}

\subsubsection{What Leading Companies Are Saying About Sustainability Value Creation Through Brand Perception and Positioning}

Natura Example

Natura Cosmeticos has long been considered a leader in sustainability, known for materials and marketing innovations that aim to reflect its tagline of "well being/being well." (Natura 2013). The Brazilian cosmetics maker has been recognized by organizations such as Corporate Knights, the U.N. Environmental Program, SustainAbility and the Boston Consulting Group. (Greenbiz 2014)

A corporate brand is not about product, but about how stakeholders view the organization and particularly its culture and value. Life cycle management helps managing expectation of stakeholders along the value chain. Which stakeholders need to be targeted in priority is a strategic decision of the company. For example, a positive brand perception helps increase customer loyalty or employee retention. Many prospective employees evaluate environmental policies as a measure of corporate value, but also sustainability programs within companies can have a significant impact on retention (The Guardian 2013).

\section{Conclusions and Outlook}

Through this chapter the authors made clear that sustainability, to be unlocked within an organization, needs to be embedded in company's strategy and have a clear link to business value creation. One need to answer first the question "what do we want to achieve" before thinking at "how" to implement a given action. From right to left, one can ask the question "how?" Life cycle management offers an holistic think-thank to identify opportunities for value creation along the entire value chain, and it provides flexible toolbox that can serve implementing sustainable actions within different departments involving different hierarchical levels. In this context, sustainability managers play an important role. They are a key actor for connecting different stakeholders vertically and transversely within the company, but also outside and linking sustainability actions into business drivers for value creation. Our experience has shown that a few key recommendations can increase the chances of success of a sustainability action in organizations. We summarize below a few key characteristics that have been proven to play a key role in operationalizing sustainability through life cycle management. 
Identify a clear value creation goal: never implement a sustainability action without first identifying the value creation goals the given initiative will contribute to achieve. The answer might be growth, enhanced reputation, improved risk management, or anything else, that is connected to value drivers generating business value within the organization. So, before thinking about implementing any LCM-based tools, first answer the questions "for what purpose?", or "what do we want to achieve?" and map a pathway that carries these actions all the way through to value creation for the organization.

Think how you can best achieve the identified business value by reverse-engineering the path to value creation. This should include links to value drivers, business benefits, implementation strategies, and ultimately to identifying the appropriate life cycle management tools to support a given sustainability initiative. One has also to keep in mind that an organization is not homogeneous and needs are different depending on the department and place in the organizational hierarchy.

The right team to reach the objective: sustainability actions are transversal to different departments, which is one of the challenges, and building the right team is important in order to ensure success. The team should include, at least a sponsor or a pilot from the department that is expecting final value creation (HR for employee engagement, marketing for product positioning, etc.) and a representative from each department involved in the value creation path. If necessary, also involve external stakeholders concerned by the value creation goal. Involve them from the beginning, i.e. from the project scoping. In large organizations, where sustainability actions are developed company-wide and are too large to be supported by a single team, they need to be subdivided into smaller actions and subtasks. Though each one of these sub-projects might not have a clear understanding of the final goal of the company, they all support the global goal and are to be monitored by the overall project sponsor, through KPI and follow-up means.

Measurable indicators: define appropriate KPIs for all the different steps of the cause-effect chain, up to the value creation. The definition of indicators and target will first align all participants on results that can be expected from the action and will then help to follow the results.

Open Access This chapter is distributed under the terms of the Creative Commons Attribution Noncommercial License, which permits any noncommercial use, distribution, and reproduction in any medium, provided the original author(s) and source are credited.

\section{References}

Accenture and United Nations Global Compact (2013) The UN Global Compact-Accenture CEO study on sustainability 2013: architects of a better world

Beiersdorf (2013) Our commitment to people. Accessed March 2015. http://www.beiersdorf.com/ sustainability/people/why-people

Bonini S, Görner S (2011) The business of sustainability: putting it into practice. McKinsey\&Company. Accessed Oct 2011. http://www.mckinsey.com/insights/energy_ resources_materials/the_business_of_sustainability_mckinsey_global_survey_results 
Bonini S, Schwartz S (2014) Profits with purpose: how organizing for sustainability can benefit the bottom line. McKinsey\&Company

Carbon Disclosure Project (2013) Sector insights: what is driving climate change action in the world's largest companies - global 500 climate change report 2013

DB Climate Change Advisors (2012) Sustainable investing: establishing long-term value and performance. Deutsche Bank

Greenbiz (2014) Natura. Accessed March 2015. http://www.greenbiz.com/blog/2014/02/04/ natura-cosmetics-sustainability-amazon

Michelin (2010) Annual and sustainable development report. From: http://www.michelin.com/ eng/media-room/press-and-news/michelin-reports/(category)/149/(year)/2010

Natura (2013) Natura report 2013. From: http://natura.infoinvest.com.br/enu/s-15-enu.html

O'Rourke D (2014) The science of sustainable supply chain. Science 344(6188):1124-1127

Starbucks (2013) Global responsibility report: goals and progress 2013. From: http://www.starbucks.com/responsibility/global-report

The Guardian (2013) Natura commits to sourcing sustainably from Amazon. From: http://www. theguardian.com/sustainable-business/natura-sourcing-sustainably-from-amazon

UNEP (2006) Background report for a UNEP guide to life cycle management - a bridge to sustainable products. United Nations Environment Programme, Paris

UNEP/SETAC (2009) Life cycle management: how business uses it to decrease footprint, create opportunities and make value chains more sustainable 